\title{
Experimental validation of error in temperature measurements in thin walled ductile iron castings
}

\author{
Pedersen, Karl Martin; Tiedje, Niels Skat
}

Published in:

International Journal of Cast Metals Research

Link to article, DOI:

$10.1179 / 136404607 \times 226838$

Publication date:

2007

Document Version

Publisher's PDF, also known as Version of record

Link back to DTU Orbit

Citation (APA):

Pedersen, K. M., \& Tiedje, N. S. (2007). Experimental validation of error in temperature measurements in thin walled ductile iron castings. International Journal of Cast Metals Research, 20(2), 84-89.

https://doi.org/10.1179/136404607X226838

\section{General rights}

Copyright and moral rights for the publications made accessible in the public portal are retained by the authors and/or other copyright owners and it is a condition of accessing publications that users recognise and abide by the legal requirements associated with these rights.

- Users may download and print one copy of any publication from the public portal for the purpose of private study or research.

- You may not further distribute the material or use it for any profit-making activity or commercial gain

- You may freely distribute the URL identifying the publication in the public portal

If you believe that this document breaches copyright please contact us providing details, and we will remove access to the work immediately and investigate your claim. 


\title{
Experimental validation of error in temperature measurements in thin walled ductile iron castings
}

\author{
K. M. Pedersen* and N. S. Tiedje
}

An experimental analysis has been performed to validate the measurement error of cooling curves measured in thin walled ductile cast iron. Specially designed thermocouples (TCs) with $\varnothing 0 \cdot 2 \mathrm{~mm}$ TC wire in $\varnothing 1.6 \mathrm{~mm}$ ceramic tube were used for the experiments. Temperatures were measured in plates with thicknesses between 2 and $4.3 \mathrm{~mm}$. The TCs were accurately placed at the same distance from the surface of the casting for different plate thicknesses. It is shown that when measuring the temperature in plates with thickness between 2 and $4.3 \mathrm{~mm}$ the measured temperature will be parallel shifted to a level $\sim 20^{\circ} \mathrm{C}$ lower than the actual temperature in the casting. Factors affecting the measurement error (oxide layer on the TC wire, penetration into the ceramic tube and variation in placement of TC) are discussed. Finally, it is shown how useful cooling curve may be obtained in thin walled castings.

Keywords: Temperature measurement, Thermocouple, Thin walled castings, Cast iron, White eutectic

\section{Introduction}

Thermal analysis of castings during solidification of e.g. cast iron can provide important information on nucleation and growth of phases during solidification. For that purpose cooling curves are used together with analysis of the microstructure to describe the solidification process.

Temperature measurement in thin walled castings can however be difficult as the volume available for placing a temperature measuring sensor is small. The volume of the measuring sensor will therefore be relatively large in comparison to the volume of the casting. Very often the measuring sensor has other thermal properties than the surrounding materials, which will influence the results of the temperature measurement. Furthermore, the solidification time is short so the response of the measuring sensor has to be very fast.

It can therefore be difficult to establish to which extent the obtained data result from the solidification process or they are influenced by the measuring technique. Temperature measurement has therefore rarely been used in thin walled cast iron. When it has been used it has mainly been used to determine solidification time ${ }^{1}$ or cooling rate at a certain temperature. $^{2}$ However, if it was known how measuring technique influences the measured results it could be possible to compensate for that. By that it could be possible to get important information about required

Department of Manufacturing Engineering and Management, Technical University of Denmark, Produktionstorvet, DK 2800 Kgs. Lyngby, Denmark

*Corresponding author, email kmp@ipl.dtu.dk undercooling for nucleation and growth during solidification.

In cast iron temperature measurement is normally performed by placing a thermocouple (TC) in the casting (see Fig. 1). However, placing a TC in the casting will influence the heat flow during solidification as the thermal properties of the TC wire and sheath material will be different from the mould and casting material. This influence will be even more pronounced in thin walled castings. By the time a thermal equilibrium is established between the TC and the metal, the solidification process is in progress or it may even be completed. Very little has however been published on this subject. Erickson and Houghton ${ }^{3}$ have made numerical simulations of the effect of a ceramic sheathed TC in a 1.5 inch $\mathrm{Pb}$ rod casting. The conclusion was that initially the TC was acting as a chill but later the ceramic was acting as an insulator increasing the local solidification time. Xue et $a l^{4}$ have made a parametric study on TC properties on transient temperature measurement. This study was based on a one-dimensional model with the TC wire in the centre of a plate. This does however not correspond well with temperature measurement in thin plates where the TC wire is placed perpendicular to the plate as shown in Fig. 1. Weathers et al. ${ }^{5}$ have simulated the effect of placing a TC in the mould, measuring the temperature close to the surface of the casting. In the case of a sand mould with the TC placed perpendicular to the surface of the casting the measured temperature can be up to $100{ }^{\circ} \mathrm{C}$ too low. This is due to that the $\mathrm{TC}$ has a much higher thermal conductivity than the sand mould. In the case of a metal mould the measured temperature in the mould can be up to $6^{\circ} \mathrm{C}$ too high due to the higher thermal conductivity of the metal 


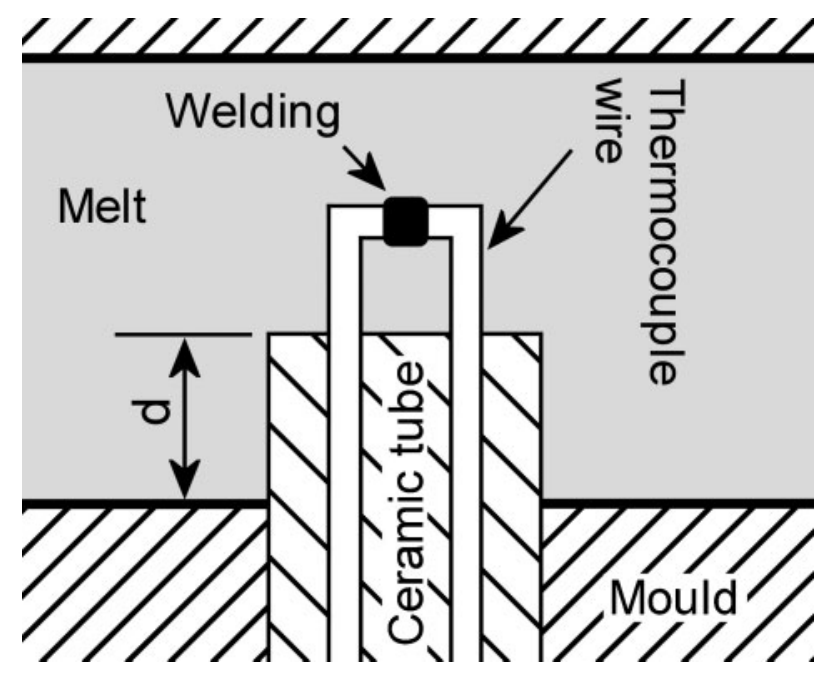

1 Thermocouple placed in thin walled casting

mould. Diószegi and Svensson ${ }^{6}$ have simulated a TC placed in a test cup for thermal analysis of cast iron. It is intended that the TC is placed in the hot spot of the casting but the simulation showed that the measured temperatures were $10-15^{\circ} \mathrm{C}$ lower than the temperature in the hot spot. Pedersen and Tiedje ${ }^{7,8}$ have examined the microstructure around a TC placed in thin walled cast iron. It was not possible to detect any difference in microstructure around the TC compared with the rest of the casting. They have also made simulations of how the TC influences the temperature locally in thin walled ductile iron castings. ${ }^{8,9}$ The simulations showed that the shape of the measured cooling curve is correct in comparison with the cooling curve in an unaffected casting. There was however a 15 to $20{ }^{\circ} \mathrm{C}$ parallel shift towards lower temperatures on the measured cooling curve in plate thicknesses of 2 to $4 \mathrm{~mm}$. This error in the measured temperature depends especially on the thermal conductivity of the TC wire while the heat capacity of the TC wire and the thermal properties of the ceramic tube only had minor influence on the measurement error. ${ }^{8,9}$

In ductile iron it can be very difficult to experimentally confirm the results of the numerical simulations. This is due to that the undercooling of ductile cast iron can be very high during the solidification and it will not be possible to detect if the measured cooling curve is a result of undercooling during solidification or error in the temperature measurement. However if the cast iron solidifies 'white', (i.e. with formation of austenite + carbides) the undercooling will be relatively small. ${ }^{10}$

The purpose of this work is therefore to confirm the simulation results in casting experiments where cast iron has solidified white.

\section{Experimental}

Ductile iron castings were produced from eutectic and hypoeutectic melts in batches of $90 \mathrm{~kg}$. The chemical analyses of the castings are shown in Table 1. The melt was superheated to $1520^{\circ} \mathrm{C}$ before being poured into a preheated ladle for magnesium treatment with a $\mathrm{Fe}-\mathrm{Si}-$ $\mathrm{Mg}$ alloy using a tundish sandwich method. The melt for each mould was then poured into a small insulated fibre cup where it was inoculated with $0 \cdot 1-0 \cdot 2 \% \mathrm{Fe}-\mathrm{Si}$ alloy before it was poured into the mould. The temperature was measured in the fibre cup with an S type TC and the casting temperature is shown in Table 1.

Two different casting layouts were used in the experiments. Casting layout A (Fig. 2a) consists of two parallel, stepped plates with thicknesses of $8,4 \cdot 3$ and $2.8 \mathrm{~mm}$. This layout was horizontally parted and the moulds were made of sodium silicate bonded sand. Casting layout B (Fig. 2b) consists of four plates with thicknesses of $1 \cdot 5,2,3$ and $4 \mathrm{~mm}$. These castings were

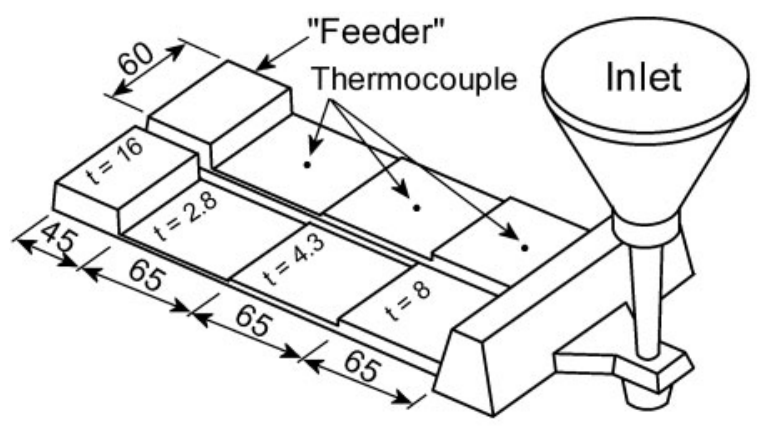

(a)

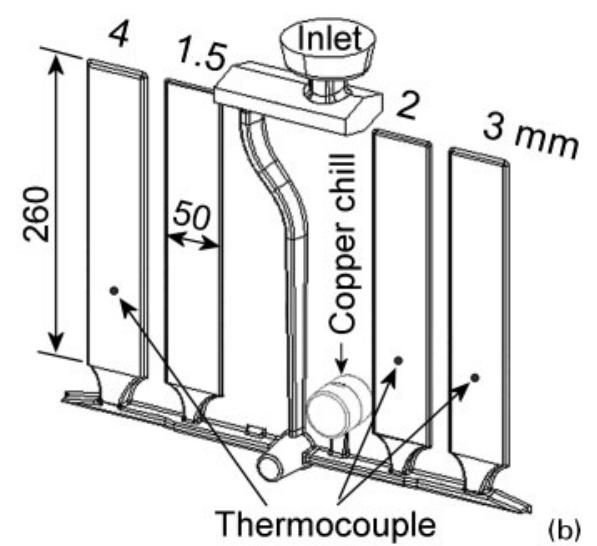

2 a casting layout A (horizontal parted) and $b$ casting layout B (vertical parted)

Table 1 Chemical analysis of castings in weight percentage $(\mathrm{CE}=\% \mathrm{C}+\mathbf{0 . 2 8} \times \% \mathrm{Si})$ and casting temperature

\begin{tabular}{|c|c|c|c|c|c|c|c|c|}
\hline Casting & C & $\mathrm{Si}$ & Mn & $P$ & $S$ & $\mathrm{Mg}$ & CE & Casting temperature, ${ }^{\circ} \mathrm{C}$ \\
\hline \\
\hline \multicolumn{9}{|c|}{ Hypoeutectic } \\
\hline G & 3.26 & $2 \cdot 67$ & 0.043 & 0.020 & 0.008 & 0.030 & $4 \cdot 01$ & 1390 \\
\hline M & 3.40 & $2 \cdot 03$ & 0.045 & 0.025 & 0.008 & 0.027 & 3.97 & 1350 \\
\hline \multicolumn{9}{|c|}{$\begin{array}{l}\text { For all castings: } \mathrm{Ni} \sim 0.017 ; \mathrm{Cr} \sim 0.032 ; \mathrm{Al} \sim 0.01 ; \mathrm{Co} \sim 0.025 ; \mathrm{Cu} \sim 0.007 ; \mathrm{Ti} \sim 0.02 ; \mathrm{V} \sim 0.03 ; \mathrm{W}<0.007 ; \mathrm{Mo}, \mathrm{Nb}, \mathrm{As}, \mathrm{Sn} \text { and } \mathrm{Pb}<0.005 ; \mathrm{Zr} \text {, } \\
\mathrm{Zn} \text { and } \mathrm{B}<0.001\end{array}$} \\
\hline
\end{tabular}



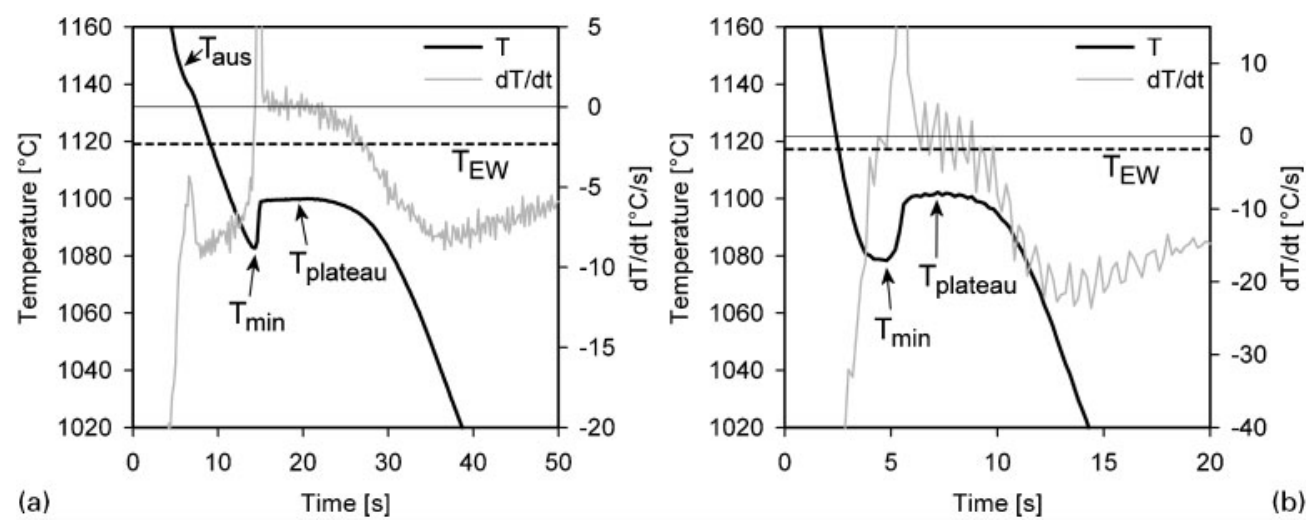

3 Cooling curves from a hypoeutectic casting M1, $4.3 \mathrm{~mm}$ plates $(15.8 \%$ carbides) and $b$ eutectic casting L3, 2.0 mm plate $(6 \cdot 4 \%$ carbides)

made in vertically parted green sand moulds on a Disamatic Moulding Machine.

The temperature was measured in the middle of each plate using percussion welded $\mathrm{K}$ type TCs with a $0 \cdot 2 \mathrm{~mm}$ wire. The TCs were placed perpendicular to the surface of the casting and a ceramic tube was used as protection material except at the measuring point as shown in Fig. 1. The ceramic tube had an outside diameter of $1.6 \mathrm{~mm}$ and the two holes had a diameter of $0.3 \mathrm{~mm}$. The penetration depth $d$ (see Fig. 1), of the ceramic tube into the plates was $3 \cdot 5 \pm 0.5 \mathrm{~mm}$ for the $8 \mathrm{~mm}$ plates and $0.5 \pm 0.2 \mathrm{~mm}$ for the other plate thicknesses. The sample rate for temperature measurement was $500 \mathrm{~Hz}$ and every 100 values were averaged to reduce noise giving a time increment of $0 \cdot 2 \mathrm{~s}$.

The microstructure was examined on cross-sections of the plates close to the TC. The samples were etched in a $3 \%$ nital solution to reveal ferrite, pearlite and carbides.

Subsequently samples were etched with $1 \mathrm{~g} \mathrm{Na}_{2} \mathrm{~S}_{2} \mathrm{O}_{5} /$ $100 \mathrm{~mL}$ distilled water $+4 \mathrm{~g}$ picric acid/100 mL ethyl alcohol to quantify the amount of carbides. ${ }^{11}$

The etching is complete when the ferrite and pearlite areas are dark and the carbides remain bright. Only castings with high content of carbides $(>5 \%)$ were used for the purpose of this investigation. None of the $8 \mathrm{~mm}$ plates had a high content of carbides.

The lamellar spacing of the white eutectic structure was measured on the etched cross-section in the centre of the plates. Only the lamellar structure with the smallest spacing was measured. This was done because it was assumed that the spacing was uniform and the lamellar structure had a random orientation relative to the examined cross-section. The lamellar spacing was measured at least at 10 different places on the cross-section.

\section{Results}

\section{Cooling curves}

Examples of cooling curves are shown in Fig. 3. In the hypoeutectic castings there is a change in the slope of the cooling at $T_{\text {aus }}$ due to growth of primary austenite dendrites, Fig. $3 a$. This is not seen in the eutectic castings (Fig. $3 b$ ). In both the eutectic and hypoeutectic castings the temperature decreases until $T_{\min }$ where there is an abrupt increase in the temperature until the cooling curve reaches a constant level or plateau at $T_{\text {plateau. }}$. These cooling curves are typical for castings with high content of carbides. ${ }^{12}$ The measured $T_{\text {plateau }}$ in each of the experiments are shown in Table 2.

The equilibrium temperature of the white eutectic $T_{\text {EW }}$ has been calculated using Thermocalc based on the chemical composition of the castings and the results are shown in Table 3 . The calculated $T_{\mathrm{EW}}$ has been compared with different experimental results. ${ }^{13-15}$ The difference between the results of Thermocalc and the experiments are within $2^{\circ} \mathrm{C}$ (see Table 3 ).

The temperature difference $T_{\mathrm{EW}}-T_{\text {plateau }}$ for the different castings is shown in Table 2. The average temperature difference $T_{\mathrm{EW}}-T_{\text {plateau }}$ is $23 \cdot 7^{\circ} \mathrm{C}$.

Table 3 Calculated metastable eutectic temperature $T_{\mathrm{EW}}$ $\left({ }^{\circ} \mathrm{C}\right)$ for chemical composition for three different castings*

\begin{tabular}{lllll}
\hline Source & Thermocalc & Ref. 13 & Ref. 14 & Ref. 15 \\
\hline Casting G & $1109 \cdot 8$ & $1109 \cdot 2$ & $1110 \cdot 5$ & $1108 \cdot 2$ \\
Casting L & $1117 \cdot 2$ & $1116 \cdot 7$ & $1118 \cdot 4$ & $1116 \cdot 2$ \\
Casting M & $1119 \cdot 1$ & $1117 \cdot 6$ & $1119 \cdot 3$ & $1117 \cdot 1$ \\
\hline
\end{tabular}

*The calculations are based on references ${ }^{13-15}$ as indicated.

Table 2 Temperatures, content of carbides and lamellar spacing in castings

\begin{tabular}{|c|c|c|c|c|c|c|}
\hline Casting & Casting layout & Plate thickness, $\mathrm{mm}$ & Carbides, \% & $T_{\text {plateau }},{ }^{\circ} \mathrm{C}$ & $T_{\text {EW }}-T_{\text {plateau }},{ }^{\circ} \mathrm{C}$ & Lamellar spacing, $\mu \mathrm{m}$ \\
\hline G1 & $A$ & $2 \cdot 8$ & $15 \cdot 4$ & $1082 \cdot 5$ & $27 \cdot 3$ & $5 \cdot 6$ \\
\hline G2 & A & $2 \cdot 8$ & $12 \cdot 4$ & $1084 \cdot 0$ & $25 \cdot 8$ & $5 \cdot 7$ \\
\hline L3 & $\mathrm{B}$ & 2 & $6 \cdot 4$ & $1101 \cdot 5$ & $15 \cdot 7$ & $4 \cdot 2$ \\
\hline L4 & B & 2 & 6.9 & $1099 \cdot 0$ & $18 \cdot 2$ & $4 \cdot 9$ \\
\hline M1 & A & $2 \cdot 8$ & $26 \cdot 9$ & $1088 \cdot 0$ & $31 \cdot 1$ & $5 \cdot 9$ \\
\hline M1 & $A$ & $4 \cdot 3$ & $15 \cdot 8$ & $1099 \cdot 5$ & $19 \cdot 6$ & $5 \cdot 5$ \\
\hline M2 & $A$ & $2 \cdot 8$ & $29 \cdot 6$ & $1094 \cdot 0$ & $25 \cdot 1$ & $5 \cdot 6$ \\
\hline M2 & A & $4 \cdot 3$ & 13.9 & $1092 \cdot 5$ & $26 \cdot 6$ & $6 \cdot 3$ \\
\hline Average & & & & & $23 \cdot 7$ & $5 \cdot 5$ \\
\hline
\end{tabular}




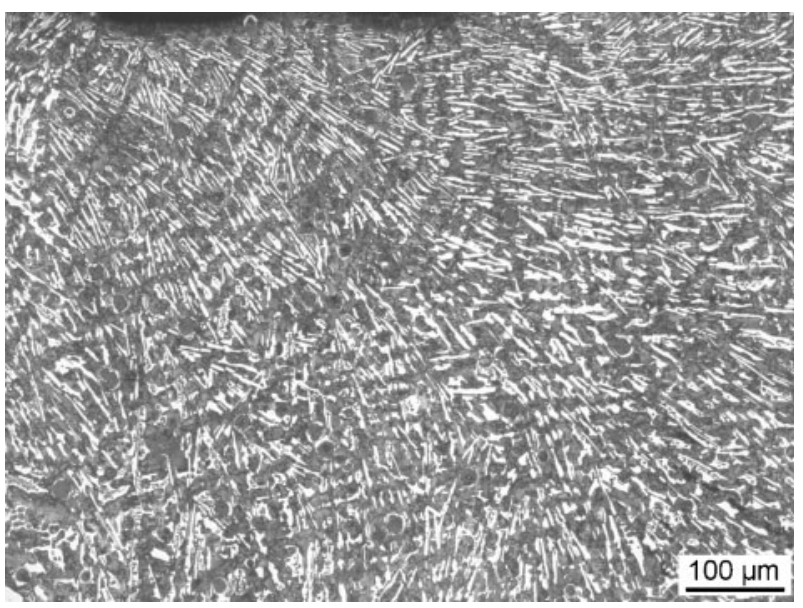

4 Microstructure from $2 \cdot 8 \mathrm{~mm}$ plate (casting M1, surface of casting placed at top of picture) showing finer carbide structure near surface and more coarse carbide structure in centre of plate (nital etched)

\section{Microstructure}

An example of the microstructure is shown in Fig. 4, which shows that during solidification primary austenite dendrites (only in the hypoeutectic castings), graphite nodules and lamellar structure of carbides and austenite are formed. With regard to the microstructure the plates can be divided into three zones: a thin surface layer with randomly oriented grains, a large zone with elongated grains from directional solidification and finally the centre of the plates with randomly oriented grains. The surface layer, which is 150 to $200 \mu \mathrm{m}$ thick, has a finer structure than in the remaining part of the castings and the structure is orientated randomly as crystals growing from certain nucleation points at the surface of the castings. In the main part of the casting the structure was coarser. There appears to have been steady state growth parallel to $\mathrm{d} T / \mathrm{d} x$, so that the grains are mainly orientated perpendicular to the surface of the casting or within an angle of $45^{\circ}$ of it. The last areas of solidification in the centre of the plates had a random orientation as in equiaxed solidification.

During solidification the lamellar spacing of carbides and austenite will decrease with increasing undercooling. ${ }^{10}$ It can therefore be assumed that the carbides had been nucleated near the surface at temperature $T_{\min }$ (see Fig. 3). As the first nucleated carbides are growing at high undercooling the lamellar spacing will be small and the growth rate high and this will give an abrupt increase in the temperature. The temperature will increase until growth rate is in equilibrium with the removal of heat from the casting to the mould. At that point steady state growth takes place at a constant temperature as seen on the cooling curves (Fig. 3). The lamellar structure of metastable eutectic will grow with a planar front from the surface to the centre of the plates.

The lamellar spacing in the centre of the plates was between 4.2 and $6 \cdot 3 \mu \mathrm{m}$, increasing slightly from thin to thick plates (see Table 2 and Fig. 5). The lamellar structure is however very disrupted due to the presence of graphite nodules which makes it difficult to measure the spacing. In addition to that the lamellar structures that were measured may not be perpendicular to the surface of the analysed cross-sections. Hence the actual

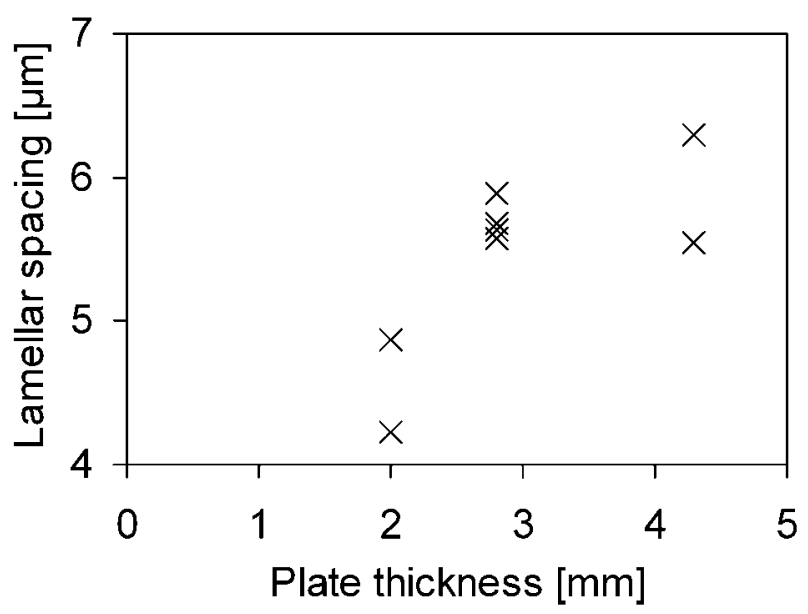

5 Measured lamellar spacing

lamellar spacing is probably little smaller than the measured lamellar spacing.

Graphite nodules were also present in the castings. These are normally nucleated in the melt and shortly afterwards surrounded by austenite shells. This will give some spheres of stable eutectics, which can grow until they are enclosed by the metastable eutectic. The solidification will therefore be a combination of stable and metastable eutectics. The growth of stable eutectic in the centre of the plates will probably ensure a positive temperature gradient which will enhance a planar front growth of the metastable eutectic. The temperature gradient will probably be small; $1^{\circ} \mathrm{C} \mathrm{mm}^{-1}$ will be a reasonable choice.

\section{Growth undercooling}

The growth of irregular eutectic such as the metastable eutectic in cast iron is governed by the following equations $^{16}$

$$
\begin{aligned}
& \lambda^{2} V=\phi^{2} \frac{K_{2}}{K_{1}} \\
& \frac{\Delta T}{V^{1 / 2}}=\left(\phi+\frac{1}{\phi}\right)\left(K_{1} K_{2}\right)^{1 / 2} \\
& \lambda \Delta T=\left(\phi^{2}+1\right) K_{2}
\end{aligned}
$$

where $\lambda$ is the lamellar spacing, $V$ is the growth velocity, $\Delta T$ is undercooling and $\phi, K_{1}$ and $K_{2}$ are constants. In the case of a temperature gradient of $8^{\circ} \mathrm{C} \mathrm{mm}^{-1}$ the constants are found to $\mathrm{be}^{17} \phi=1 \cdot 8, \quad K_{1}=6.03 \times$ $10^{9} \mathrm{~K} \mathrm{~s} \mathrm{~m}^{-2}$ and $K_{2}=0.752 \times 10^{-6} \mathrm{~m} \mathrm{~K}$.

The time from the nucleation of the carbides to the end of solidification was $\sim 25 \mathrm{~s}$ for a $4.3 \mathrm{~mm}$ plate and $8 \mathrm{~s}$ for a $2 \mathrm{~mm}$ plate. This will give an average solidification velocity in the range from 86 to $125 \mu \mathrm{m} \mathrm{s}^{-1}$. According to equations (1) and (2) this will give a lamellar spacing in the range of 1.8 to $2 \cdot 2 \mu \mathrm{m}$ and an undercooling in the range of 1.5 to $1.8^{\circ} \mathrm{C}$ (see Table 4). The calculated lamellar spacing is low in comparison to the measured spacing of $\sim 5.5 \mu \mathrm{m}$. This may be due to that the temperature gradient can have an influence on the laminar spacing. In the case of $\mathrm{Al}-\mathrm{Si}$, an other irregular eutectic system, the influence of the temperature gradient was found to be ${ }^{18}$ 


$$
\begin{aligned}
& \lambda=\frac{A}{V^{1 / 2} G^{1 / 3}} \\
& \Delta T=\frac{B V^{1 / 2}}{G^{1 / 2}}
\end{aligned}
$$

where $A$ and $B$ are constants and $G$ is temperature gradient. By combining that with equations (1) and (2) and the constants given by Magnin and Trivedi, ${ }^{17}$ the constant $A$ is found to be $4.02 \times 10^{-7} \mathrm{~K}^{1 / 3} \mathrm{~m}^{7 / 6} \mathrm{~s}^{-1 / 2}$ and the constant $\mathrm{B}$ to $1.42 \times 10^{4} \mathrm{~K}^{3 / 2} \mathrm{~m}^{-1} \mathrm{~s}^{1 / 2}$. Assuming a temperature gradient of $G=1^{\circ} \mathrm{C} \mathrm{mm}^{-1}$ the lamellar spacing will be in the range of 3.6 to $4.3 \mu \mathrm{m}$ (see Table 4) which is closer to the measured lamellar spacing. The undercooling will then be in the range of $4 \cdot 2$ to $5 \cdot 0^{\circ} \mathrm{C}$ (see Table 4 ). As the average difference $T_{\text {EW }}-T_{\text {plateau }}$ was $23.7^{\circ} \mathrm{C}$ it can be assumed that the measured temperatures in the plates were $\sim 19^{\circ} \mathrm{C}$ too low. This corresponds very well with what was shown by the numerical simulations. ${ }^{8,9}$

\section{Discussion}

\section{Effect of segregation}

During solidification there can be some segregation of $\mathrm{Si}$ to the austenite. This would lower the Si content of the liquid and by that increase the $T_{\mathrm{EW}}{ }^{13-15}$ The effect of segregation is however small in the first part of the solidification. ${ }^{19}$ Furthermore during growth of the metastable eutectic Si can be rejected to the liquid as the Si content in the carbide phase is negligible. At high content of carbides the $T_{\mathrm{EW}}$ will decrease and at low content of carbides the $T_{\mathrm{EW}}$ will increase as for stable eutectics. ${ }^{20}$ For an intermediate content of carbides as in the present castings it can therefore be assumed that the changes in the $T_{\mathrm{EW}}$ will be small during solidification.

\section{Effects related to measuring of temperature}

For the same plate thickness there is some variation in the temperature difference $T_{\mathrm{EW}}-T_{\text {plateau }}$ for the different experiments (see Table 2). This can arise from several factors: the TCs are not placed exactly at the same position; oxides on the surface of the TC wire and melt that is forced into the ceramic tube that protects the TC wire.

Concerning the position of the TC (see Fig. 1), simulations have shown that increasing the penetration depth, $d$, will decrease the error in the temperature measurement. ${ }^{8,9}$ Small variations in placing the TCs in the castings could give some variation in the level of the measured temperature.

The variation in temperature measurement can also be a result of variation in the exact location of the measuring point (volume) where the TC wire is in electric contact with the melt, also denoted as measuring point in Fig. 6. Depending on the conditions there can be an oxide layer surrounding the TC wire close to the ceramic tube (TC wire A in Fig. 6) or there can be

Table 4 Calculated lamellar spacing and growth undercooling for different temperature gradients and growth velocities

\begin{tabular}{lrrrr}
\hline Temperature gradient $G,{ }^{\circ} \mathrm{C} \mathrm{mm}$ & 8 & 8 & 1 & 1 \\
Growth velocity $V, \mu \mathrm{m} \mathrm{s}^{-1}$ & 86 & 125 & 86 & 125 \\
Lamellar spacing $\lambda, \mu \mathrm{m}$ & 2.2 & 1.8 & 4.3 & 3.6 \\
Growth undercooling $\Delta T,{ }^{\circ} \mathrm{C}$ & 1.5 & 1.8 & 4.2 & 5.0 \\
\hline
\end{tabular}

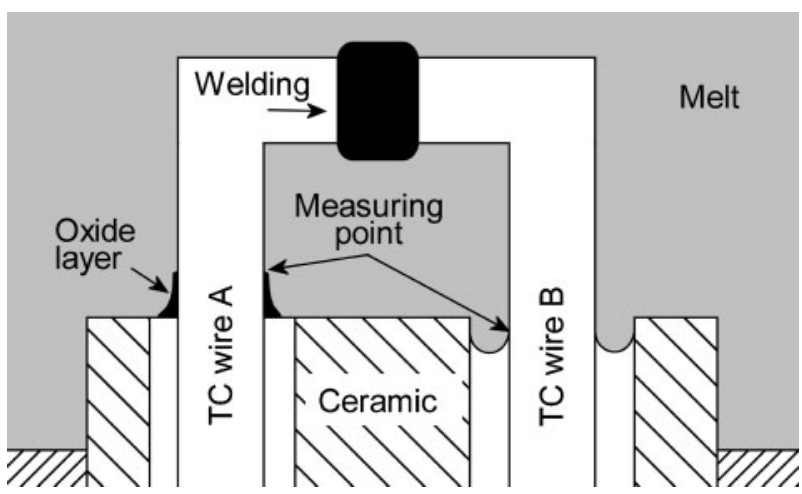

6 Variations in position of measuring point due to either oxide layer (TC wire A) or small penetrations (TC wire B)

penetration of melt into the ceramic tube (TC wire $\mathrm{B}$ Fig. 6). ${ }^{7,8}$

The oxide layer can be formed on the surface of the melt and can envelope the TC wire when the melt hits the TC wire during the filling of the mould. The oxide layer can however be dissolved or be worn off the TC wire if there is a sufficient flow of melt passing the TC wire. ${ }^{7,8}$ In the present castings the casting layouts were designed to insure a sufficient amount of melt flowing past the TCs (see Fig. 2). The melt will then clean the surface of the TC wire, and if there is any oxide layer left this will only be placed close to the ceramic tube as shown at wire A in Fig. 6. If there is some oxide layer left on the TC wire this will however move the measuring point and this will have an influence on the measuring error. ${ }^{7,8}$ Hence, variations of the amount of oxide layer can give variations of the measuring error.

Penetration can occur especially if the diameter of the holes in the ceramic tube is too large in comparison with the diameter of the TC wires. It can also be initiated by a pressure shock wave in the melt which can be created when the melt hits a blind end of the gating system or at the end of the mould filling. ${ }^{21}$ The penetration can normally be observed on the measured cooling curve as there will be an abrupt decrease in the measured temperature, especially if the penetration is large., Such an abrupt decrease on the cooling curves was not observed in the present castings and it can therefore be assumed that there was only negligible, if any, penetration. The difference between the diameters of the TC wires and the holes in the ceramic tubes was also very small, limiting the possibilities of melt penetration into the ceramic tubes.

The above mentioned points show that a lot of different factors may influence the temperature measurement in thin walled castings. The validation of the error in temperature measurements in thin walled castings based on a metastable eutectic solidification is therefore only valid for experiments performed under similar conditions. This especially involves the geometry and placement of the TCs, the chemical composition, including the treatment of the melt and the casting layout, especially concerning the amount of melt flow passing the TCs. Great care must be taken when placing the TCs in the moulds in order to minimise variation in results between measurements.

Owing to the limited number of experimental results, it is not possible to predict whether the plate thickness 
could have an influence on the temperature measurements. The numerical simulations have however shown that with the present experimental conditions, especially concerning the placement of the TC in the casting characterised by the depth $d=0.5 \mathrm{~mm}$ in Fig. 1, the variations due to difference in plate thicknesses will be small for the geometry used here. ${ }^{8,9}$ The present experiments comply well with modelling results in that respect.

\section{Temperature measurement in thin walled ductile cast iron}

In the present work, the experimental process conditions are similar to those used in the foundry industry for casting thin walled ductile iron components.

The samples analysed here contained a large amount of metastable carbides which is necessary for the thermal analysis, but not desired in production. Some of the plates in the present work did also solidify as stable eutectic reaction. Normally hypereutectic melts are used for thin walled castings, but there is no indication that the carbon equivalent will have an influence on the temperature measurement. The present method of temperature measurement can therefore also be used for recording cooling curves in thin walled ductile cast iron. Some main recommendations for that will be:

(i) place the TC perpendicular to surface of the plate in order to minimise the influence on the melt flow during the filling of the mould

(ii) some melt should pass the TC during the filling of the mould in order to clean the TC wire for oxides and to preheat the TC

(iii) the TC wire and ceramic tube should be as thin as possible

(iv) the $\mathrm{TC}$ wire should be naked at the measuring point to insure a good thermal contact with the melt

(v) the thermal properties, especially the thermal conductivity should be as close to the moulding material as possible. Especially for ceramic tubes the thermal conductivity can vary from about $1 \mathrm{~W} \mathrm{~m}^{-1} \mathrm{~K}^{-1}$ (close to that of sand) up to $30 \mathrm{~W} \mathrm{~m}^{-1} \mathrm{~K}^{-1}$ (close to that of steel)

(vi) the TCs should be placed as accurate as possible in the castings.

\section{Conclusion}

An assessment of the measurement error when measuring cooling curves in thin walled ductile iron castings has been performed. The assessment is based on casting experiments where the solidification involved metastable eutectics, which solidifies at low undercooling. In average, the recorded thermal analysis temperatures in thin wall sections will be lower than the real temperature in the order of $20^{\circ} \mathrm{C}$. This corresponds well with what have been shown previously by numerical simulations.

This error is valid only for experiments performed under similar conditions, including TC geometry and placement, casting geometry including melt passing the TC and chemical composition and melt treatment.

\section{Acknowledgement}

This work has partly been financed by Technical University of Denmark and partly by the Danish Research Council for Technology and Production Sciences, which are greatly acknowledged.

\section{References}

1. J. M. Borrajo, R. A. Martinez, J. A. Sikora and R. E. Boeri: ISIJ Int., 2002, 42, 257-263.

2. D. M. Stefanescu, L. P. Dix, R. E. Ruxanda, C. Corbitt and T. S. Piwonka: AFS Trans., 2002, 110, 1149-1162.

3. W. C. Erickson and A. V. Houghton: AFS Trans., 1977, 85, 59-64.

4. X. Xue, R. Luck, B. Dawsey and J. T. Berry: AFS Trans., 2004, 112, 37-54.

5. J. Weathers, A. Johnson, R. Luck, K. Walters and J. T. Berry: AFS Trans., 2005, 113, 253-263.

6. A. Diószegi and I. L. Svensson: Mater. Sci. Eng. A, 2005, A413A414, 474 479 .

7. K. M. Pedersen and N. Tiedje: 'Temperature measurement during solidification of thin wall ductile cast iron. Part 1: Theory and experiment', Measurement, 2005.

8. K. M. Pedersen: 'Solidification and microstructure of thin walled ductile cast iron', PhD thesis, Department of Manufacturing Engineering and Management, Technical University of Denmark, Denmark, 2005.

9. K. M. Pedersen and N. Tiedje: 'Temperature measurement during solidification of thin wall ductile cast iron. Part 1: Theory and experiment', Measurement, 2005.

10. P. Magnin and W. Kurz: Metall. Trans. A, 1988, 19A, 1955-1963.

11. R. E. Ruxanda, D. M. Stefanescu and T. S. Piwonka: AFS Trans., 2002, 110, 1131-1148.

12. M. Hillert and V. V. Subba Rao: 'The solidification of metals', No. 110, 204-212; 1968, London, The Iron and Steel Institute.

13. M. Booth: The Brit. Foundryman, 1983, 76, 35-45.

14. R. Doepp and S. Schwenkel: Mater. Sci. Eng. A, 2005, A413-A414, 334-338.

15. J. van Eegham, G. Devos, J. Plessers and O. Cure: Int. Cast Met. J., 1977, 2, 57-63.

16. H. Jones and W. Kurz: Z. Metallkde., 1981, 72, 792-797.

17. P. Magnin and R. Trivedi: Acta Metall. Mater., 1991, 39, 453-467.

18. B. Tololi and A. Hellawell: Acta Metall., 1976, 24, 565-573.

19. J. Lacaze: Acta Mater., 1999, 47, 3779-3792.

20. L. Nastac and D. M. Stefanescu: AFS Trans., 1995, 103, 329-337.

21. P. Larsen and N. Tiedje: Proc. 66th Would Foundry Cong., Istanbul, Turkey, September 2004, Foundrymen's Association of Turkey, Paper 44. 